\title{
A Fire Hazard Assessment Using Sentinel Imagery; A Case Study Over Gippsland Australia
}

\author{
Sanjeev Kumar Raut \\ Survey Department, Ministry of Land Management, \\ Co-operatives and Poverty Alleviation \\ Minbhawan, Kathmandu, Nepal
}

\begin{abstract}
Accurate and the efficient rapid mapping of the fire-damaged areas are the most fundamental things for any places to retain from environmental loss. To support the fire management, make definite strategy and planning, and restore the vegetation, it is important to detect the area before and after the fire damages. Under climate change conditions, heat and drought may trigger tough fire regimes in terms of number and dimension of fires. To deliver the rapid information of the area damaged by the fires, Burned Area Index (BAI), Normalized Burned Ratio (NBR) and their versions are applied to map burned areas from high-resolution optical satellite data. The new MSI sensor aboard Sentinel-2 satellites records the more spectral information in the red edge spectral region making it more convenient to the development of new indices for the burned area mapping. Recently, Australia had confronted a devastating bushfire recorded in the history of the nation. In this project, NBR deployed to detect burned areas at around $10 \mathrm{~m}-20 \mathrm{~m}$ spatial resolution based on pre and post-fire Sentinel-2 images. A dNBR (differentiated Normalized Burned Ratio) was calculated while burn severity was mapped as purposed by United States Geological Survey (USGS). It observed that more than half of the East Gippsland region i.e. about $53 \%$ of the area affected by the wildfire while $38 \%$ remained unburned and $8.4 \%$ showed the regrowth.
\end{abstract}

Keywords:- Fire Severity, Normalized Burned Ratio (NBR), Normalized Burned Ratio difference (dNBR), Sentinel, United States Geological Survey (USGS).

\section{INTRODUCTION}

Starting from the very late 2019 to early 2020 colloquially known as the Black Summer, Australia has gone through a ruinous stage of massive bushfire [1]. Hundreds of fires burnt especially in the southeast of the country during the summer [2]. The major fire occurred between December and January and resulting in the adaptation of nature to it. The ecologist and historian Stephen Pyne stated Australia being the fire continent [3]. We were made aware of the increasing temperature, which were caused extreme fire. Because of this, Australia has

\author{
David Nhemaphuki, Rebanta Aryal, Prakash Lakandri, \\ Department of Geomatics Engineering \\ Kathmandu University \\ Dhulikhel, Kavre, Nepal
}

been wrestling to cope with the seriousness brought by the fire.

The accurate information of the wrecked area is provided by the satellite imagery during these havocs. Satellite imagery helps with the mapping of fire disrupted places to support fire management, take account of environmental loss, planning strategies and check on ecological restoration [4]. Remote sensing (RS) is the perfect acquisition when it comes to evaluating the burned area to help in further prevention and improvements [5]. Within it, images of the spatial resolution of fire-damaged areas are considered as the necessary requisite to aid in fire management. Apart, spectral resolution can also be used in the mapping of the affected area by using two different methods: single or multi-temporal satellite images. These image helping ecological parameters in the approximation of the fire intensity by field viewing[6]

Ae technology advances, there are more approaches introduced to take the mapping. Among them, the threshold-based classification of dNBR has been in use to measure the seriousness of the burn. NBR shows the efficient fire index for computing the burn area over Alaska using Landsat images [7]. Walz and his groups had successfully applied the NBR ratio for identifying the severity zone in Southern Australia [8]. Burn severity data and maps can aid in developing emergency rehabilitation and restoration plans. Lately, High spatial resolution optical data like MSI sensor abroad Sentinel-2 (S2) satellite imagery makes it easy to access the area with severe burn and compare pre-fire and post-fire mapping. The goal of this study is to compute the fire zone area over EastGippsland using multi-temporal remote sensing images.

\section{STUDY AREA}

Eastern and North-Eastern Victoria was the major affected regions during the bush fire. Our study area is East Gippsland that lies in the Gippsland region covering an area of 27,531 sq.km. Gippsland region is the Southeastern part of the Victoria state, Australia. There are industries like agriculture, timber production, fishing and tourism in East Gippsland while Bairnsdale is famous for commerce and retail trade. The study area consists of Alpine, Snowy River and Croajingolong National Parks. 


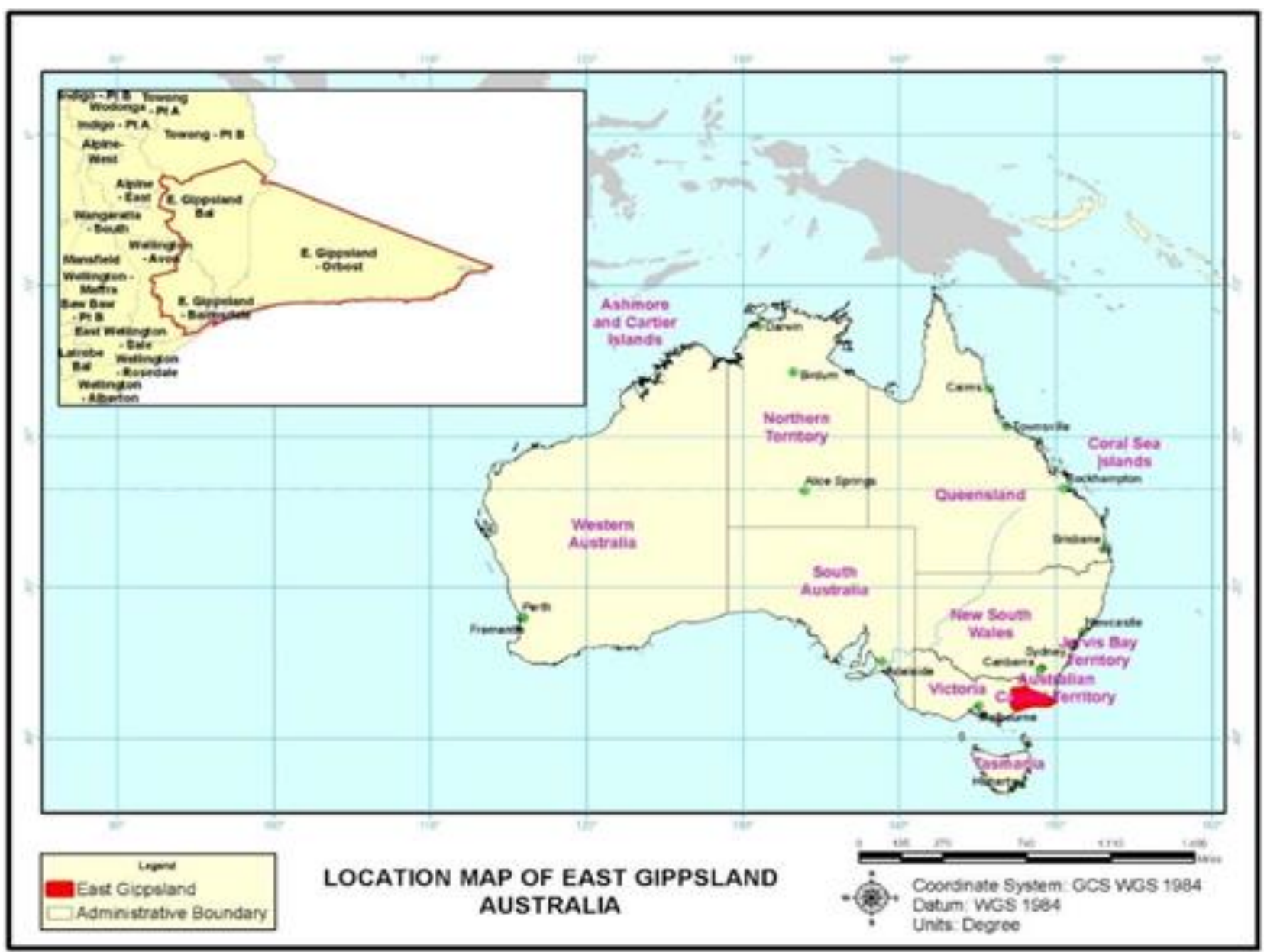

Fig 1:- Location Map of East Gippsland Australia

\section{DATASET AND METHODOLOGY}

\section{A. Data used}

Sentinel-2 images of July 2019 and March, April 2020 were used for pre and post-fire purpose respectively. The Sentinel-2 provided with wide-swath, high-resolution, multi-spectral imaging help particularly in the monitoring of vegetation, soil and water cover, as well as coastal areas. For Level-1C, the granules, also called tiles, are $100 \times 100 \mathrm{~km}^{2}$ ortho-images in UTM/WGS84 is freely available images that have the spatial resolution of 10-60 meter depending upon the bands used. (https://scihub.copernicus.eu/dhus/\#/home). The boundary data of the study area was download and was used to subset the study area from the Sentinel-2. https://www.igismap.com/australia-shapefile-download/)

\section{B. Software Used}

Google Earth Engine is a cloud-based platform for scientific analysis and visualization of geospatial datasets, for academic, non-profit, business and government users [9]. Earth Engine hosts satellite imagery and stores it in a public data archive that includes historical earth images to recent images, which are made available for global-scale data mining. It also provides APIs and other tools to enable the analysis of large datasets. 


\section{METHODOLOGY}

The figure 2 shows the overall methodology for this research. The methodology contains image pre-processing, followed by calculation of indices and burn severity map.

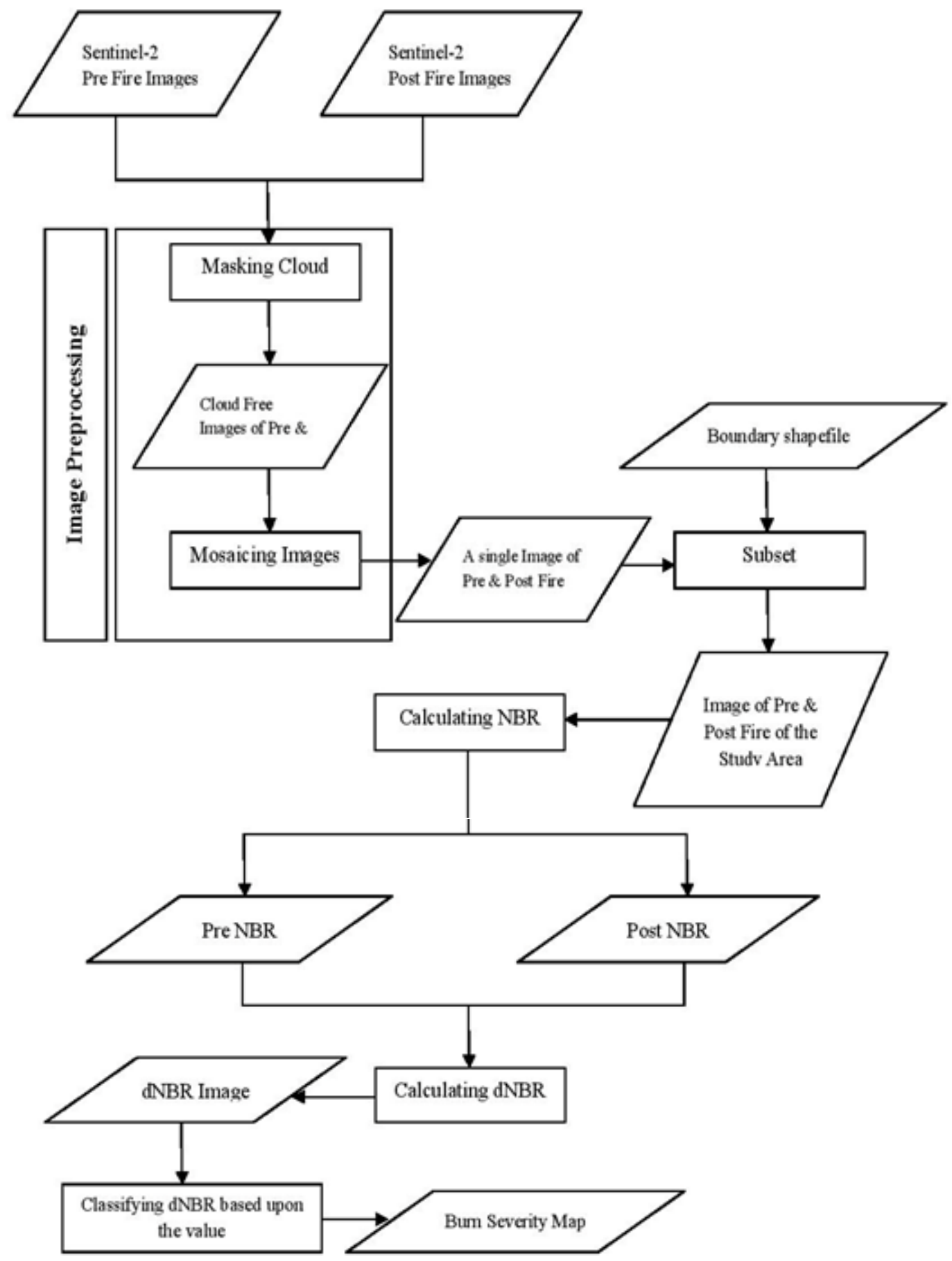

Fig 2:- Overall Methodology

\section{Image Pre-processing}

Sentinel-2 images having less than $20 \%$ clouds coverage used and the cloud areas masked before performing other analysis. The sentinel-2 image provides $16^{\text {th }}$ band "QA60" having $60 \mathrm{~m}$ resolution containing information about the cloud and used for cloud masking the image. After applying the cloud mask, a mosaic of the image created and then a subset image of the study area obtained by clipping the mosaic image with the use of vector file of the study area. Sentinel-2 Level-1C images already provided with radiometric and geometric corrections including ortho-rectification and spatial registration based on the global reference system. 


\section{Calculation of Indices}

The most commonly used metrics for the burned area and burn severity mapping, derived from satellite data NBR [10].

$$
N B R=\frac{N I R-S W I R}{N I R+S W I R}
$$

Healthy vegetation shows the high reflectance in near infrared while low reflectance in the shortwave infrared in the spectrum. The burned areas indicate low reflectance in the near-infrared and high reflectance in the shortwave infrared band. Thus, high and low NBR value indicates healthy vegetation and recently burned areas respectively.

\section{Calculating pre-fire NBR}

Sentinel-2 images of July 2019 used to calculate the pre-fire NBR of the study area.

\section{Calculating post-fire NBR}

Sentinel-2 images of February 2019 used to calculate the post-fire NBR of the study area.

\section{Calculating differentiated NBR (dNBR)}

The difference between the pre-fire and post-fire NBR obtained from the images had used to calculate the $\boldsymbol{d N B R}$ [11]. The formula used to calculate $\boldsymbol{d N B R}$ as illustrated below:

\section{$d N B R=N B R_{\text {pre }}-N B R_{\text {post }}$}

$>$ Burn Severity

The calculated $\boldsymbol{d N B R}$ used to estimate burn severity. A higher value of $\boldsymbol{d N B R}$ indicates more severe damage, while areas with negative $\boldsymbol{d N B R}$ values may indicate re-growth following a fire. They used to estimate not only the soil burn severity, but also the likelihood of future downstream impacts due to flooding, landslides, and soil erosion.

In this study, we have used burn severity levels proposed by USGS depending upon the value of the $\boldsymbol{d N B R}$ as given in table 1 .

\begin{tabular}{|lcc|}
\hline Severity Level & dNBR Range (scaled by $10^{3}$ ) & dNBR Range (not scaled) \\
\hline Enhanced Regrowth, high (post-fire) & -500 to -251 & -0.500 to -0.251 \\
\hline Enhanced Regrowth, low (post-fire) & -250 to -101 & -0.250 to -0.101 \\
\hline Unburned & -100 to +99 & -0.100 to +0.99 \\
\hline Low Severity & +100 to +269 & +0.100 to +0.269 \\
\hline Moderate-low Severity & +270 to +439 & +0.270 to +0.439 \\
\hline Miderate-high Severity & +440 to +659 & +0.440 to +0.659 \\
\hline High Severity & +660 to +1300 & +0.660 to +1.300 \\
\hline
\end{tabular}

Table 1:- Burn severity levels obtained calculating dNBR, proposed by USGS

\section{RESULT AND ANALYSIS}

Figure 3 shows the final output of the burn severity map. The fire had spreaded over the whole Gippsland region. The darker the red color higher the severity and viceversa. While analyzing result North-Western and the central part of East Gippsland, Orbost seems to be more affected as the maximum of the area falls under a more severe burn area indicated by dark red.

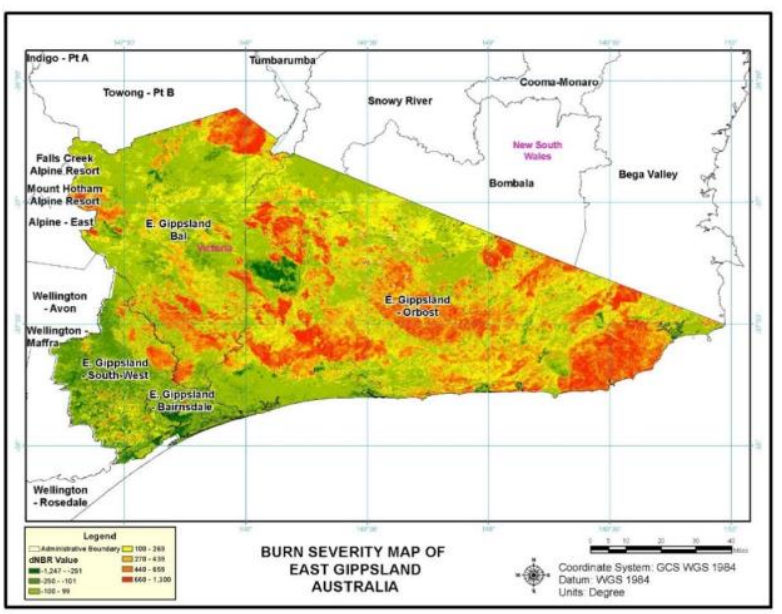

Fig 3:- Burn Severity Map of East Gippsland Australia.
Figure 5 showing bar diagram prepared from the Pre and Post NBR pixel count for different pixel range values. In Lower NBR range value, there is the increase in the total no. of pixels while in Post NBR result showing more bare or burn area. In the higher range of pixel value, the total no. of pixel decreases showing the decrease in vegetation after the fire because a low value indicates a bare ground or recently burnt areas while a high NBR value indicates healthy vegetation. Lower Post NBR value has higher the severity of Fire and higher Post NBR value lowers the severity of Fire.

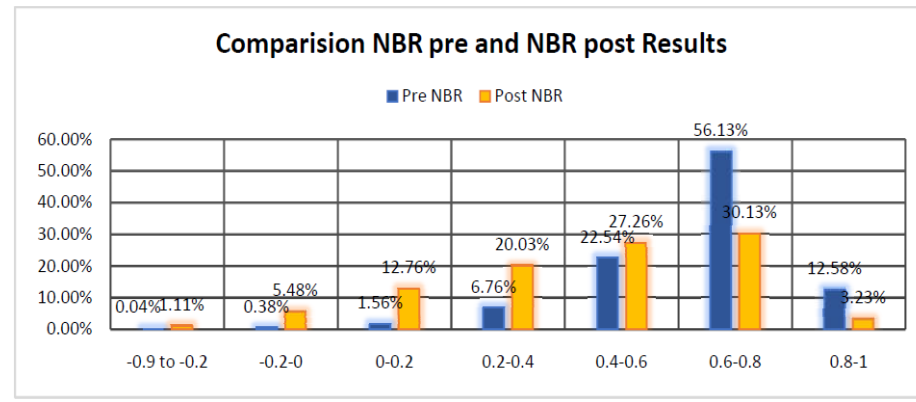

Fig 4:- Comparison between NBR pre and NBR post Results. 
The area and percentage of each severity class were calculated and shown in Table 2 and figure 5. The result shows that $7.84 \%$ has high severity, about $26 \%$ has moderately severity, $19.71 \%$ has low severity and about $46.43 \%$ area falls under the unaffected area due to fire.

\begin{tabular}{|c|c|c|c|}
\hline S. N & Burn Severity & $\begin{array}{c}\text { Percentage } \\
(\%)\end{array}$ & Area (sq.km) \\
\hline 1 & High Severity & 7.84 & 2158.43 \\
\hline 2 & Moderately High Severity & 13.71 & 3774.50 \\
\hline 3 & Moderately Low Severity & 12.31 & 3389.06 \\
\hline 4 & Low Severity & 19.71 & 5426.36 \\
\hline 5 & Unburned & 38.04 & 10472.72 \\
\hline 6 & $\begin{array}{c}\text { Enhanced Regrowth } \\
\text { (Low) }\end{array}$ & 6.89 & 1896.88 \\
\hline 7 & $\begin{array}{c}\text { Enhanced Regrowth } \\
\text { (High) }\end{array}$ & 1.5 & 412.96 \\
\hline \multicolumn{2}{|c|}{ Total } & 100 & 27531 \\
\hline
\end{tabular}

Table 2:- Burn severity and affected area

From pie chart diagram, it is seen that more than 50 percent of East Gippsland was affected by the Fire.

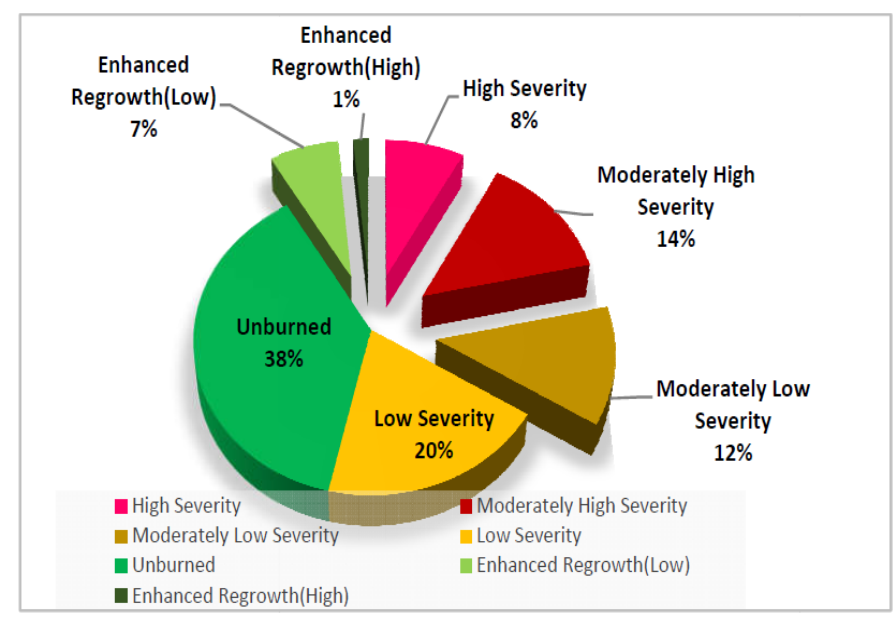

Fig 5:- Pie Chart showing the burn Severity in East Gippsland Australia.

\section{CONCLUSION}

Australia has a long history of bush fire but the fire occurred in late 2019 to 2020 regarded among the most destructive wildfire in Australian history. A burn map showing the burn severity level was prepared for the East Gippsland lying in the northeast part of Victoria State, which was the most affected region in the state. The dNBR is an effective method to access the burn severity due to fire and applied to our study successfully. About $53.5 \%$ of the total area of East Gippsland affected by the wildfire while about $46.5 \%$ of the area remained unharmed.

\section{REFERENCES}

[1]. T. Burgess, J. R. Burgmann, S. Hall, D. Holmes, and E. Turner, "Black Summer: Australian newspaper reporting of the nation's worst bushfire crisis," p. 30, 2020.

[2]. "Catastrophic wildfires in southeastern Australia in 2019-20 | NOAA Climate.gov.” [Online]. Available: https://www.climate.gov/news-features/eventtracker/catastrophic-wildfires-southeastern-australia2019-20. [Accessed: 12-Jul-2020].

[3]. S. J. PYNE, FIRE A BRIEF HISTORY, vol. 53, no. 9. University of Washington Press, 2001.

[4]. T. Long et al., " $30 \mathrm{~m}$ resolution global annual burned area mapping based on landsat images and Google Earth Engine," Remote Sens., vol. 11, no. 5, pp. 1-30, 2019.

[5]. A. E. Cocke, P. Z. Fulé, and J. E. Crouse, "Comparison of burn severity assessments using Differenced Normalized Burn Ratio and ground data," Int. J. Wildl. Fire, vol. 14, no. 2, pp. 189-198, 2005.

[6]. J. E. Keeley, "Fire intensity, fire severity and burn severity: A brief review and suggested usage," Int. J. Wildl. Fire, vol. 18, no. 1, pp. 116-126, 2009.

[7]. J. Epting, D. Verbyla, and B. Sorbel, "Evaluation of remotely sensed indices for assessing burn severity in interior Alaska using Landsat TM and ETM+," Remote Sens. Environ., vol. 96, no. 3, pp. 328-339, 2005.

[8]. Y. Walz, S. W. Maier, S. W. Dech, C. Conrad, and R. R. Colditz, "Classification of burn severity using Moderate Resolution Imaging Spectroradiometer (MODIS): A case study in the jarrah-marri forest of southwest Western Australia," J. Geophys. Res. Biogeosciences, vol. 112, no. 2, pp. 1-14, 2007.

[9]. N. Gorelick, M. Hancher, M. Dixon, S. Ilyushchenko, D. Thau, and R. Moore, "Google Earth Engine: Planetary-scale geospatial analysis for everyone," Remote Sens. Environ., vol. 202, pp. 18-27, 2017.

[10]. C. H. Key and N. C. Benson, "Landscape assessment: Remote sensing of severity, the Normalized Burn Ratio," FIREMON

[11]. K. A. Murphy, J. H. Reynolds, and J. M. Koltun, "Evaluating the ability of the differenced Normalized Burn Ratio (dNBR) to predict ecologically significant burn severity in Alaskan boreal forests," Int. J. Wildl. Fire, vol. 17, no. 4, pp. 490-499, 2008. 